NBER WORKING PAPER SERIES

\title{
INFORMATION CONTENT OF EQUITY ANALYST REPORTS
}

\author{
Paul Asquith \\ Michael B. Mikhail \\ Andrea S. Au \\ Working Paper 9246 \\ http://www.nber.org/papers/w9246
NATIONAL BUREAU OF ECONOMIC RESEARCH
1050 Massachusetts Avenue
Cambridge, MA 02138
October 2002

We wish to thank SP Kothari, Grace Pownall, Philip Stocken, Beverly Walther, Richard Willis, and workshop participants at MIT, Wharton, the SECARC, and the AAA Annual Meeting for helpful comments and suggestions. We also acknowledge the research assistance of Jeff Braun. The views expressed herein are those of the authors and not necessarily those of the National Bureau of Economic Research.

(C) 2002 by Paul Asquith, Michael B. Mikhail and Andrea S. Au. All rights reserved. Short sections of text, not to exceed two paragraphs, may be quoted without explicit permission provided that full credit, including (C) notice, is given to the source. 
Information Content of Equity Analyst Reports

Paul Asquith, Michael B. Mikhail and Andrea S. Au

NBER Working Paper No. 9246

October 2002

JEL No. G11, G14, G24, M41

$\underline{\text { ABSTRACT }}$

This paper investigates the market reaction to the information released in security analyst reports. It shows that the market reacts significantly and positively to changes in recommendation levels, earnings forecasts, and price targets. While changes in price targets and earnings forecasts both provide information to the market, revisions in price targets have a larger and more significant impact than comparable revisions in earnings forecasts. The text of the report is also a significant source of information as it provides the justifications supporting an analyst's summary opinion. When all of this information is considered simultaneously, some of it, notably the earnings forecasts, is subsumed. The results further show that analysts correctly predict price targets slightly over $50 \%$ of the time. Finally, the valuation methodology used does not seem to be correlated with either the market's reaction or the analyst's accuracy.

Paul Asquith

Sloan School of Management

Massachusetts Institute of Technology

50 Memorial Drive

Cambridge, MA 02142

and NBER

pasquith@mit.edu

Andrea S. Au

Sloan School of Management

Massachusetts Institute of Technology

50 Memorial Drive

Cambridge, MA 02142

andreau@mit.edu
Michael B. Mikhail

Fuqua School of Business

Duke University

Box 90120

Durham, NC 27708

mmikhail@duke.edu 


\section{Introduction}

This paper investigates the association between market returns and the content of security analysts' reports. In addition, it provides the first detailed catalog of the elements in a typical analyst report. An analyst's report is the culmination of a process that includes the collection, evaluation, and dissemination of information related to a firm's future performance. The majority of these reports include three key summary elements: earnings forecasts, a stock recommendation - such as buy, sell, or hold - and a price target. In addition, many reports present extensive quantitative and descriptive analysis supporting these summary elements. ${ }^{1}$

Previous research on analyst reports primarily examines revisions in only the first two summary elements: stock recommendations and earnings forecasts. We extend this research by incorporating the contents of analyst reports in their entirety rather than just individual elements such as the summary recommendation. One problem in evaluating stock recommendations alone is that there are a limited number of recommendation levels. For example, although analysts have five distinct recommendations - strong buy, buy, hold, sell, and strong sell - at their disposal, they are generally reluctant to use the two negative ratings. ${ }^{2}$ By incorporating the gradations available in the analysts' price targets and the reports' contents, we overcome many of the disadvantages caused by the use of a few discrete recommendation categories. ${ }^{3}$ Our approach to this analysis is captured by the quote "In the end, stock ratings and target prices are just the skin and bones of analysts' research. The meat of such reports is in the analysis, detail,

\footnotetext{
${ }^{1}$ Recently some firms have announced that they will to expand this list of summary elements to include information such as the projected price volatility and the stock's dividend outlook. See "Merrill Lynch Announces Major Changes to Stock Ratings and Compensation Systems for Research Analysts."

${ }^{2}$ An often-cited rationale for this avoidance is that an analyst's salary and bonus may be linked to quantifiable measures such as his firm's underwriting fees or commissions generated by his recommendations, outcomes that may be facilitated by the issuance of favorable reports. In addition, analysts traditionally relied on company management for information and thus had a reason to maintain good relations with them. The 2000 SEC Regulation FD, which requires firms to publicly disseminate all material information, presumably reduces this incentive. ${ }^{3}$ Mikhail, Walther, and Willis (2002) report that approximately 55\% of all recommendations are buys or strong buys, $39 \%$ are holds and only $6 \%$ are sells or strong sells. See also Barber, Lehavy, McNichols, and Trueman (2001). Recent announcements by Wall Street Firms to change to only three ratings codify their actual behavior. See "Should You Trust Wall Street's New Ratings?"
} 
and tone." This is especially true for reiterations, which represent almost two thirds of the analyst reports in our database.

Using a database constructed from analyst reports issued during 1997-1999, we examine if, after controlling for changes in earnings forecasts and summary recommendations, the market's response to the release of a security analyst report varies with price target changes and other information contained in the report. Our analysis shows that changes in the summary stock recommendations, earnings forecasts, and price targets all provide independent information to the capital markets. In particular, incorporating changes in analyst price targets dramatically increases the fit of our regression results over that obtained from earnings forecast revisions and discrete recommendations alone.

Adding proxies for other information in a report, such as the strength of the written arguments made to support an analyst's opinion, significantly alters our results. As expected, the stronger the justifications provided in the report, the larger the market's reaction to the report. After including this additional information in our model, our results show that although the market reaction is still correlated with changes in price targets, the significance of earnings forecast revisions decreases. Moreover, while our recommendation downgrades remain statistically negative, the significance of recommendation upgrades is eliminated. Recent reductions in the recommendation levels used by some firms (e.g., from five to three by Merrill Lynch and Goldman Sachs) will likely further increase the market's reaction to price targets and other information contained in analyst reports. 5

We extend our analysis to examine if the market treats an analyst's report differently based on the type of recommendation revision. For example, is a change in a firm's price target, earnings forecasts or an analyst's justifications for an opinion more important in a report that reiterates an old recommendation or in a report that provides an upgrade or downgrade? We find

\footnotetext{
${ }^{4}$ See "When a Stock's Rating and Target Collide."

5 See "Should You Trust Wall Street's New Ratings?"
} 
that the contents of an analyst's report receive the most scrutiny in the case of downgrades. The changes in a firm's price target, earnings forecasts and the strength of a report's arguments are all positively correlated with the market's response. Also, the coefficient on our proxy for a relationship between a brokerage and a firm under analysis is statistically negative. This suggests that the market discounts good news and amplifies bad news when the brokerage is not independent of the firm. The strength of an analyst's arguments and price target changes are also important in the case of reiterations. However, the market places little weight on these examined factors in the case of upgrades.

Finally, we examine the accuracy of price targets and the effects of the valuation methodology employed by an analyst. We consider a price target prediction to be accurate if the analyzed firm's stock price equals the projected price at any time during the 12-month period following the release of a report. Using this definition of accuracy, we find that approximately $54 \%$ of analysts' price targets are achieved or exceeded. The remaining $46 \%$ of firms achieve an average of $84 \%$ of the price target within 12 months. The level of optimism exhibited by an analyst, as measured by the projected change in a firm's stock price, appears to be inversely related to the probability of achieving a particular target.

We find that the valuation methodology used by analysts is not significant in explaining either the market's reaction to the analyst's recommendations or to their accuracy in predicting price targets. In fact, most analysts use a simple earnings multiple valuation model. Only a minority use Net Present Value or other discounted cash flow approaches favored by finance textbooks and MBA curriculums.

In Section 2 we summarize prior research. Section 3 describes the data and sample selection criteria as well as a typical analyst report. We discuss our empirical results in Section 4. Sections 5 and 6 provide results on price target accuracy and valuation methodologies and Section 7 concludes. 


\section{Prior Research}

Over the past two decades, security analysts' reports have been the subject of extensive empirical and experimental work. These prior investigations are primarily related to either the market's reaction to earnings forecast revisions or revisions in analysts' recommendations. Most of this work shows positive (negative) abnormal returns for upward (downward) earnings forecast revisions or new buy (sell) recommendations. For example, Abdel-Khalik and Ajinkya (1982) find significant abnormal returns during the publication week of forecast revisions by Merrill Lynch analysts. Similarly, Lys and Sohn (1990) present evidence consistent with forecast revisions having information content (see also Stickel (1991)).

Research examining short-window returns associated with revisions in analyst recommendations has also found a positive association between abnormal returns and the direction of a recommendation change. Lloyd Davies and Canes (1978) indirectly examine the market reaction to security analyst recommendations by studying stock suggestions appearing in the Wall Street Journal's "Heard on the Street" column. They find an event day return of $0.93 \%$ $(-2.37 \%)$ for new buy (sell) recommendations. ${ }^{6}$ More recently, Womack (1996) uses First Call data to directly examine price reactions for stock recommendation changes to and from the most extreme buy and sell categories. He finds that stocks added to (removed from) strong buy lists earned size adjusted returns of $2.98 \%(-1.94 \%)$ while stocks added to (removed from) strong sell lists earned size adjusted returns of $-4.69 \%(0.32 \%)$ in the 3-day event period surrounding the release of the recommendation revision. In most of these studies, reiterations of a previous forecast or recommendation are ignored. In this paper, by examining the content of an analyst report beyond the summary recommendation, we are able to draw conclusions about reiterations as well as revisions.

Our work is also related to research investigating security returns conditional on examining both earnings forecast and recommendation revisions simultaneously. For example,

\footnotetext{
${ }^{6}$ See also Bjerring, Lakonishok, and Vermaelen (1983), Elton, Gruber, and Grossman (1986), Liu, Smith, and Syed (1990), Beneish (1991), and Stickel (1995).
} 
Francis and Soffer (1997) find that neither earnings forecast revisions nor stock recommendations completely incorporate the information in the other signal. They also show that when a report is summarized by a favorable stock recommendation, investors rely on earnings forecast revisions to a greater extent. Stickel (1995), in addition to the summary recommendation and earnings forecast revisions, includes proxies for the magnitude of the recommendation revision, the analyst's reputation, the size of the analyst's brokerage house, and the analyzed firm's information environment. His results are consistent with those of Francis and Soffer indicating that earnings forecast revisions are informative even in the presence of a summary recommendation. He also finds that company size and analyst reputation affect returns for buy recommendations, while the magnitude of the recommendation revision and brokerage size affect returns for sell recommendations.

Although Francis and Soffer and Stickel's studies include a broad cross-section of potential factors (other than price targets), which could contribute to the market's reaction to a new recommendation, adjusted $\mathrm{R}^{2} \mathrm{~s}$ for their models are low. The adjusted $\mathrm{R}^{2}$ for Stickle's study is $1 \%$ for his buy regression and $2 \%$ for his sell regression, suggesting that important pieces of the puzzle were missing. Francis and Soffer get an adjusted $\mathrm{R}^{2}$ of $5 \%$ for their complete crosssectional model. In this paper, we investigate the effects of additional report information, not included in earlier work, such as price targets and the strength of the arguments made. These additional sources of information result in adjusted $\mathrm{R}^{2} \mathrm{~s}$ of over $24 \%$.

Finally, our work is related to Hirst, Koonce, and Simko (1995) who use an experimental setting to investigate how potential investors assess the information contained in security analysts' reports conditional on the characteristics of both the analyst and the report. They alter the source of the report (independent brokerage or analyzed firm's investment bank), the report's conclusions (favorable or unfavorable), and the strength of the arguments made in the report (strong or weak). Based on psychology research, they predict and find that when an unfavorable report is issued, investors seek out other information to corroborate the unfavorable news. 
In particular, Hirst, Koonce, and Simko find that when a report is unfavorable the strength of the arguments contained in an analyst's report affects investors' judgments. This result conflicts with Francis and Soffer (1997) who find that investors are more likely to rely on other information in cases of good news reports. Furthermore, Hirst, Koonce, and Simko report that experimental investors react more strongly to negative reports from analysts who lack independence. The effects associated with a lack of independence are similar to those found in Michaely and Womack (1999), which documents that the mean excess returns around a buy recommendation revision are lower when the recommendation is made by an underwriter than by an unaffiliated brokerage.

Two other recent papers incorporate price targets. Bradshaw (2002) documents a correlation between price targets, recommendations, and earnings based measures on a sample of 103 analyst reports. Brav and Lehavy (2001), using a large database of price targets, find a significant market reaction to price targets both unconditionally and conditional on contemporaneous recommendation and earnings forecast revisions. They also regress these three

variables and find adjusted $\mathrm{R}^{2} \mathrm{~s}$ of almost $8 \%$. Our paper differs in that we examine a large sample of actual analyst reports and our analysis provides information beyond earnings forecasts, recommendations, and price targets. We demonstrate that other information, such as the strength of the analyst's justifications, are also important and actually subsume some of the information available in earnings forecasts and recommendation revisions.

\section{Sample Selection and Data Description}

\subsection{Sample selection}

Our analysis uses a total of 1,126 complete analysts' reports written by 56 unique sellside analysts from 11 different investment banks covering 46 industries as provided by the Investext database. Investext features current research reports from more than 630 investment banks, brokerage houses, and research firms worldwide including, but not limited to, Credit Suisse First Boston, Lehman Brothers, Merrill Lynch, Morgan Stanley Dean Witter, and 
Salomon Smith Barney. Each report was read in its entirety and coded by hand for 30 separate data fields.

There are a number of financial databases that catalog and summarize earnings forecasts and analyst recommendations (e.g., Zacks Investment Research and I/B/E/S). To the best of our knowledge, however, there are currently no databases that provide similarly compiled information that includes analyst price targets and other information, such as valuation methodologies or justifications for recommendations made, typically found in an analyst report. The only way to collect this information is to read individual analyst reports and hand code the contents. To generate our sample, we select equity analyst reports that were written in 1997, 1998, or 1999 by a member of Institutional Investor's All-America Research Team. ${ }^{7}$ We chose these analysts because they have been independently recognized as top analysts in their given industries. Furthermore, prior research finds that All-America Research Team members supply more accurate earnings forecasts than other analysts (e.g., Stickel (1992)) and their recommendation revisions result in a stronger stock market reaction than that observed for a typical analyst (see Stickel (1995)).

During our sample period, the number of analysts receiving top honors in the Institutional Investor survey each year ranged from 76 to 84 . However, since many analysts were multiple year winners, only 153 unique analysts are represented in our sample. In addition to being written bya recent All-America Research Team member, the report must also be available through both the Zacks Investment Research (Zacks) and Investext Databases. When we began our initial analysis, Investext did not allow users to search reports by analyst. As a result, we used Zacks to generate a list of reports written by our sample of analysts. ${ }^{8}$ Zacks identified approximately 7,100 reports that met our year and analyst criteria. These analyst reports

\footnotetext{
7 To qualify for inclusion in the sample, an analyst must have achieved at least one "First Team" ranking during 1996-1999.

${ }^{8}$ Investext has since released a newer version that provides more search alternatives including a category for report author.
} 
consisted of both company and industry reports. ${ }^{9}$ All of these analyst reports were then crossreferenced in the Investext database using company and brokerage identifiers as well as report dates obtained from Zacks.

In our matching, 21 analysts could not be included in our sample because the investment firms that employ them do not provide reports to Investext (e.g., Goldman Sachs). We realize that this introduces a potential bias into our sample, as only firms willing to make their reports publicly available are included within our sample. Moreover, five of the 99 industries for which Institutional Investor issues a ranking, Accounting and Tax Policy, Convertibles, Equity Derivatives, Multi-Industry, and Quantitative Research, do not require that analysts follow any specifically identified firms. We excluded these categories, which represented seven additional analysts, from our sample. In total, we omit 28 analysts from our All-America Research Team sample, leaving 125 unique analysts.

Unfortunately, the Investext database is less complete than Zacks and we were only able to find a subset of the Zacks reports. ${ }^{10}$ More specifically, Investext contains fewer analysts and does not contain as many reports by the analysts it does list. Of the analyst reports listed in Zacks, the percentages found in Investext were less than $13.1 \%, 12.4 \%$, and $50.3 \%$ in 1997,98 , and 99 respectively. Our final sample includes 1,126 reports consisting of 262 upgrades, 739 reiterations, and 125 downgrades, written by 56 analysts.

Having identified our sample, the primary challenge remaining was determining the correct announcement date for each report. Firms often release key information contained in the analyst report before the actual report is dated and made available. As a consequence, the announcement dates given by many analyst databases, including Zacks, often differ from the

\footnotetext{
${ }^{9}$ We omit Industry reports from our sample. We find that these reports did not usually contain new company specific information but rather served as a summary across several firms. Furthermore, if an analyst reported new information about a company and/or changed his recommendations in an industry report, he usually issued a concurrent separate company report as well.

${ }^{10}$ Zacks also appears to be incomplete. Investext contains some reports by particular analysts that were not identified in our search of Zacks. In both Investext and Zacks, coverage significantly improves in the latter part of our sample period.
} 
date given on the report. ${ }^{11}$ Obtaining the correct date is clearly important, given that our analysis involves examining the market reaction to information releases from the reports. We explored various sources of news releases including Dow Jones and Lexis-Nexus, as well as finance websites such as Yahoo, to determine the correct information announcement date for a random sample of 50 reports. We found that Zacks was particularly accurate in reporting recommendation release dates and thus we used its dates as our announcement dates whenever possible.

\subsection{Typical analyst report}

Table 1, Panels A and B, presents summary statistics on average values and frequency of reporting for several of the data fields that we collect from each analyst report. All reports contain a summary stock recommendation and our table is organized by recommendation category, such as upgrade to strong buy or downgrade to hold, as well as by the combined categories all upgrades, all reiterations, or all downgrades, and a total sample column. ${ }^{12}$ The majority of the reports also include summary earnings forecasts and price targets. Additional data included in each report in support of the authoring analyst's forecasts and opinions are presented in Table 1. These include the prevalence of accounting statement forecasts and segment data analyses, data regarding relationships between the analyst's brokerage and the firm, data regarding the valuation methods employed, and the analyst's qualitative justifications of his or her recommendation.

Consistent with other studies and recent press reports, we find that analysts rarely issue sell or strong sell recommendations. Line 2 of Table 1, Panel A, shows that only $0.5 \%$ of the recommendations in our sample fall into these two categories. In contrast, $30.8 \%$ of the

\footnotetext{
${ }^{11}$ In our sample $58.6 \%$ of all report dates matched the announcement date exactly, leaving $41.4 \%$ of the analyst reports dated differently from the Zacks dates. Of the reports where dates differed, $92 \%$ of the time the report date fell after the corresponding Zacks date.

${ }^{12}$ An analyst's report generally indicates whether its recommendation is an upgrade, downgrade or reiteration. In cases where the previous recommendation is indeterminate, we use the previous recommendation as conveyed by Zacks to classify the report.
} 
recommendations are classified as strong buy, $40.0 \%$ as buy, and $28.7 \%$ as hold. We also find that the majority of reports issued across all recommendations are reiterations. The last three columns before the Total column in Table 1, Panel A, show that upgrades, downgrades, and reiterations represent $23.3 \%, 11.1 \%$, and $65.6 \%$ of our sample, respectively.

One hundred percent of our reports contain a summary stock recommendation and almost all reports also provide EPS forecasts; $99.1 \%$ for the current fiscal year and $95.3 \%$ for at least one subsequent year. There is no notable difference in the percentage of reports that contain one-year earnings forecasts across recommendation types. At $89.6 \%$, the downgrade to hold recommendations are the only category of subsequent year forecasts to fall below $90 \%$.

Price targets, which are the analyst's price forecasts, are only present in $72.6 \%$ of analysts' reports. They are given as either a point estimate or a range that the stock price is expected to achieve within the next 12 months. Price targets, while not as common as recommendations or earnings forecasts in the total sample, are even less frequent for unfavorable reports. In our sample, while over $90 \%$ of all strong buy or buy recommendations include price targets, only $11.1 \%$ of hold reiterations and $50.6 \%$ of hold downgrades include these projections. Overall, $95.8 \%$ of upgrades, $65.5 \%$ of reiterations, and $65.6 \%$ of downgrades include price forecasts. It appears that analysts' reluctance to issue negative information via downgrades extends to price targets as well, although not as strongly. In fact, $62.8 \%$ of downgrades that do not include a price target in the current report had one in the prior report. In light of recent events, some investment banks are specifically requiring their analyst to disclose price targets in reports with a positive recommendation (e.g., Merrill Lynch). In addition, these banks are including a stock chart indicating the points at which they changed their recommendations or price targets. $^{13}$

The projected stock price increase, i.e. the percentage the price target is above the current price, varies systematically across recommendation categories. For example the third line under

\footnotetext{
${ }^{13}$ See “ Merrill Lynch Announces Major Changes to Stock Ratings and Compensation Systems for Research Analysts."
} 
the category Price Targets in Table 1, Panel A, shows that the average projected increase over the current stock price for an upgrade to strong buy or buy are $34.6 \%$ and $22.6 \%$, respectively. Interestingly, reiterations have even higher stock price increases than upgrades for each recommendation category. For the entire sample, reiterations project an average $36.6 \%$ increase while upgrades project a $28.9 \%$ average increase. Price targets below current market price are fairly uncommon. Even in unfavorable reports such as a downgrade to hold, the average projected increase is a positive $5.5 \%$.

In addition to price targets and earnings forecasts, we compile information on income statements, balance sheets, statements of cash flow, and segment forecasts. Based on our sample, financial statement forecasts are not disclosed as frequently as earnings or price forecasts. Of the reports in our sample, $28.5 \%$ contain income statement forecasts, $5.1 \%$ contain balance sheet forecasts, and $17.1 \%$ contain statement of cash flow forecasts. Although the percentages of upgrade and downgrade reports that contain financial statement forecasts are similar (46.6\% and 40.0\%, respectively), these percentages are much higher than those of reiterated reports, which contain these forecasts only $20.1 \%$ of the time. Very few analyst reports contain geographic (3.6\%), product (4.2\%), or segment information $(10.0 \%)$.

We also collect information on existing relationships between the company and the investment bank writing the report. Analysts are required to provide this information in their report. Of the firms examined, $52.5 \%$ have an underwriting relationship with the analyst's brokerage. The underwriting relationship is similar across both upgrades and reiterations at $53 \%$. Downgrades are only slightly less frequent with an underwriting relationship in $46.4 \%$ of the cases examined. Differences in current holdings are more varied. Investment banks have holdings in $84.2 \%$ of the firms analyzed. Holdings of company stock exist in $68.3 \%, 63.2 \%$ and 93.4\% of upgrades, downgrades and reiterations, respectively.

Next, we document the valuation methods used by the analysts in Table 1, Panel A, under the category Valuation Models. We find that $99.1 \%$ of analysts mention they use some sort of earnings multiple (e.g., a price to earnings ratio, a price to EBIT multiple, or a relative price to 
earnings ratio). Only $12.8 \%$ of analysts report using any variation of discounted cash flow in computing their price targets. Notably, the discounted cash flow method is much more prevalent in downgraded reports, $20.8 \%$ compared to $13.7 \%$ and $11.1 \%$ in upgrades and reiterations, respectively. Valuation models based on asset multiples are used in $25.1 \%$ of all reports and $22.9 \%, 27.6 \%$ and $15.2 \%$ of upgrades, reiterations and downgrades, respectively. Very few analysts use alternative valuation methodologies. Other valuation methods not falling into one of the three categories discussed above are observed in less than $3.6 \%$ of our sample. All analysts who mention a valuation method use an earnings multiple. That is, the $0.9 \%$ that do not mention an earnings multiple do not mention any valuation method.

Finally, Table 1, Panel B, catalogs the analyst's qualitative justifications of his or her recommendation. Positive and negative remarks are recorded for sixteen specific criteria: value, relative value, sales growth, earnings growth, new product introductions, new projects, cost efficiencies, expectations met, mergers and acquisitions, repurchase programs, industry climate, management, international operations, leverage, competition, and risk. Only $3 \%$ of our sample (34 reports) do not contain some justification of the recommendations.

\subsection{Model variables}

Our empirical analyses require us to calculate several variables not directly provided in the analyst reports we examine (see Table 1, Panel C). The first model variable we compute is the percentage change in an analyst's earnings forecast for a firm (EARN_REV). This is the new earnings forecast divided by the old earnings forecast minus 1 . Since the current report does not usually contain the previous earnings forecast, we collect previous earnings forecasts from Investext, from the report immediately preceding the one in our sample. We obtain previous earnings forecasts for 1,029 reports, $91.4 \%$ of our sample. ${ }^{14}$ We find an average earnings

\footnotetext{
${ }^{14}$ We cannot be certain that the earnings forecast we obtained is from the report immediately prior to our sample report due to reports missing on Investext, however errors from obtaining earlier forecasts should weaken our results. This is discussed further in the results section.
} 
forecast change of $4.1 \%$ and $4.0 \%$ for strong buy and buy upgrades, respectively. In contrast, unfavorable reports such as a downgrade to buy or hold generally experience reductions in forecasted earnings. Downgrades to buy result in an average reduction in earnings forecasts of $7.3 \%$, while downgrades to hold experience a reduction of $4.5 \%$. Overall, upgrades, downgrades, and reiterations experience earnings forecast changes of $4.1 \%,-2.1 \%$, and $-3.6 \%$ respectively.

The second model variable we compute is the percentage change in an analyst's price target forecast for a firm (TGT_REV). This is the new price target divided by the old price target minus 1. Since the current report rarely contains the previous price target, we collect previous price target information, as available from Investext as described above. We obtain previous price targets for 664 reports or $59.0 \%$ of our sample. ${ }^{15}$ We find an average price target change of $2.8 \%$ for the total sample. The average price target changes are $13.8 \%$ and $5.5 \%$ for strong buy and buy upgrades, respectively. In contrast, we find price target changes of only $1.0 \%$ and $2.7 \%$ for strong buy and buy reiterations. Downgrades to buy result in an average reduction in price targets of $7.0 \%$, while downgrades to hold experience an average reduction of 7.5\%. Overall, upgrades, downgrades, and reiterations experience average price target changes of $11.4 \%,-7.3 \%$, and $1.9 \%$, respectively. Except for downgrades to hold and strong sell, the average price target revisions are more positive than average earnings forecast revisions. Earnings forecast revisions and price target changes are the only model variables not computed for every report in our sample.

To measure the relationship between the firm analyzed and the analyst's employer, we construct another model variable, a proxy for underwriter affiliation (UND_HLD). This indicator variable takes on a value of 0 if no relationship between the analyst's brokerage and the firm exists, 1 if the brokerage is an underwriter of the firm or has current holdings in the firm,

\footnotetext{
${ }^{15}$ We cannot be certain that the price target we obtained is from the report immediately prior to our sample report due to reports missing on Investext, however errors from obtaining earlier targets should weaken our results. This is discussed further in the results section.
} 
and 2 if the brokerage is both an underwriter and has current holdings. The average UND_HLD is similar for upgrades and downgrades with a value of 1.2 and 1.1, respectively. Reiterations are slightly higher with an average value of 1.5.

We model the analyst's qualitative justifications for his or her opinion by constructing a "strength of arguments" variable (STR_ARG). This variable is computed by aggregating the number of positive remarks less the number of negative remarks from Table 1, Panel B. In general, upgrades have an average strength value of 4.8 compared to 2.1 for reiterations and -0.3 for downgrades. It is notable that downgrades still result in an average score close to zero. This is consistent with the desire to minimize management retaliation since company management is a key source of information and future underwriting business.

Next, we measure the market's reaction to the release of analyst reports with CAR, our fifth model variable. CAR is the five-day market adjusted cumulative abnormal return centered on the report release date. The average mean CAR for all firms in our sample is a negligible $0.5 \%$. Consistent with our expectations and prior research, we find a statistically positive average mean return of $4.5 \%$ for upgrades, a statistically significant mean return of $-6.6 \%$ for downgrades and an insignificant mean reaction of $0.3 \%$ for reiterations. Breaking up report types into specific summary categories yields similar results. Upgrades to strong buy and buy result in significant mean returns of $4.7 \%$ and $4.1 \%$, respectively. Downgrades to buy and hold result in significant negative mean returns of $-7.0 \%$ and $-6.4 \%$, on average. The mean CARs for upgrades and downgrades are all statistically different from zero with a two-tailed probability less than 0.01. Reiterations are generally small and insignificant with one exception: reiterations of hold recommendations have an average mean return of $-1.1 \%$. Reports representing hold upgrades, sell and strong sell downgrades or reiterations have too few observations to draw any reliable conclusions as to average market reactions. ${ }^{16}$

\footnotetext{
${ }^{16}$ We find that a particular report's direction (e.g., upgrade, downgrade, or reiteration) tends to dominate the specific recommendation level. The differences in the observed market reaction between strong buy upgrades and buy upgrades, buy downgrades and hold downgrades, or strong buy reiterations versus buy reiterations are all insignificant. As such, although we provide descriptive statistics for reports categorized by both report type and summary recommendation, our primary empirical tests are performed on reports categorized by direction only.
} 


\section{Empirical results}

\subsection{Earnings, recommendations, and price target revisions}

We first replicate prior research on our sample and document that the market reacts to earnings forecast and recommendation revisions contained in a security analyst report at the time of its release. Market reaction is measured by five-day market adjusted returns centered on the report's release date. This allows for possible delays by a brokerage in delivering its forecasts to Zacks or for leaks of the information prior to its public release. We then investigate whether this reaction is affected by revisions in a firm's price target. Later in this section we also investigate whether the strength of the arguments used in the report or the presence of an underwriting relationship or current holdings affect the market's reaction.

Table 2 estimates the following regression using ordinary least squares:

$$
\begin{gathered}
\mathrm{CAR}_{\mathrm{j}, \mathrm{t}}=\alpha_{0}+\alpha_{1} \mathrm{EARN}_{-} \mathrm{REV} \mathrm{j}_{\mathrm{j}, \mathrm{t}}+\alpha_{2} \mathrm{UP} \_\mathrm{GR}_{\mathrm{j}, \mathrm{t}}+\alpha_{3} \mathrm{DOWN} \mathrm{GR}_{\mathrm{j}, \mathrm{t}}+\alpha_{4} \mathrm{TGT} \_R E V_{\mathrm{j}, \mathrm{t}} \\
+\alpha_{5} \mathrm{STR} \_\mathrm{ARG}_{\mathrm{j}, \mathrm{t}}+\alpha_{6} \mathrm{UND}_{-} \mathrm{HLD}_{\mathrm{j}, \mathrm{t}}+\varepsilon_{\mathrm{j}, \mathrm{t}}
\end{gathered}
$$

where the variables are defined as follows:

$\mathrm{CAR}_{\mathrm{j}, \mathrm{t}}=\quad$ five-day market adjusted cumulative abnormal return for firm $\mathrm{j}$ centered on the report release date $t$;

EARN_REV $V_{j, t}=$ Percentage change in the analyst's earnings forecast for firm $\mathrm{j}$ at time $\mathrm{t}$ computed as [(earnings forecast at time $\mathrm{t} /$ earnings forecast at time $\mathrm{t}-1)-1$ ];

$\mathrm{UP}_{-} \mathrm{GR}_{\mathrm{j}, \mathrm{t}}=\quad$ a variable taking on the value 1 for reports issued for firm $\mathrm{j}$ at time $\mathrm{t}$ that indicates the analyst's recommendation has been upgraded, 0 otherwise;

DOWN_GR $\mathrm{j}_{\mathrm{t}, \mathrm{t}}=$ a variable taking on the value 1 for reports issued for firm $\mathrm{j}$ at time $\mathrm{t}$ that indicates the analyst's recommendation has been downgraded, 0 otherwise;

TGT_REV ${ }_{j, t}=\quad$ Percentage change in the analyst's projected price target for firm $\mathrm{j}$ at time $\mathrm{t}$ computed as [(price target at time $\mathrm{t} /$ price target at time $\mathrm{t}-1)-1]$;

STR_ARG $G_{\mathrm{j}, \mathrm{t}}=\quad$ a variable computed by aggregating the number of positive remarks less the number of negative remarks related to 16 specific criteria: value, relative value, sales growth, earnings growth, new product introductions, new projects, cost efficiencies, expectations met, mergers and acquisitions, repurchase programs, industry climate, management, international operations, leverage, competition, and risk; 
UND_HLD $D_{j, t}=\quad$ a variable taking on the value 0 if no relationship between the analyst's brokerage and the firm exists, 1 if the brokerage is an underwriter of the firm or has current holdings in the firm, and 2 if the brokerage is both an underwriter and has current holdings;

$\varepsilon_{\mathrm{j}, \mathrm{t}}=\quad$ assumed normally distributed error term with zero mean and constant variance.

This regression is estimated using EARN_REV $V_{\mathrm{j}, \mathrm{t}}$ and $T G T \_R E V_{\mathrm{j}, \mathrm{t}}$ from prior reports released within 60 days of our report. As described above, we collect prior earnings and price targets from the same analyst's Investext report immediately preceding ours. Since Investext is not complete, i.e. it does not contain all reports, there is a chance that another report was released after the prior report we collect. If so this will make our regression results weaker. Since an analyst usually writes a minimum of six reports a year on the companies they follow, we do not include revisions from prior reports issued more than 60 days before our report. This restriction minimizes the effect of missing reports. ${ }^{17}$

Columns 1,2, and 3 of Table 2 present the results from estimating regressions for earnings forecast revisions, recommendation revisions, and changes in price targets individually (i.e., only including those proxy variables in the OLS regressions). If, as documented in prior research, the market reacts to changes in earnings forecasts and the recommendation contained in the typical security analyst report, the coefficients EARN_REV in column 1 and UP_GR in column 2 will be positive while DOWN_GR in column 2 will be negative. If as predicted, analyst price target revisions have information, TGT_REV in column 3 will be positive.

Consistent with prior research, we find that the coefficient on EARN_REV is positive and statistically significant, $(0.0545, \mathrm{t}=2.81$, one-tailed $\mathrm{p}<0.01)$, suggesting that increases (decreases) in earnings forecasts are associated with positive (negative) abnormal returns. Also in agreement with existing work, we find that reiterations, upgrades, and downgrades are

\footnotetext{
${ }^{17}$ Using longer time periods, e.g. 60 to 90 days or all reports over 90 days, reduces the significance levels of the variables EARN_REV and TGT_REV.
} 
associated with insignificant, positive, and negative abnormal returns, respectively. The intercept in column 2 is the mean abnormal return associated with a reiteration $(-0.0044, t=-$ 1.12, two-tailed $\mathrm{p}>0.10$ ). Column $2 \mathrm{~A}$ calculates the mean returns associated with an upgrade $(0.0473, \mathrm{~F}=44.84$, one-tailed $\mathrm{p}<0.01)$ or downgrade $(-0.0894, \mathrm{~F}=66.77$, one-tailed $\mathrm{p}<0.01)$ by summing $\left(\alpha_{0}+\alpha_{2}\right)$ and $\left(\alpha_{0}+\alpha_{3}\right)$, respectively.

The results for price target revisions are reported in column 3. As predicted, TGT_REV is positive and statistically significant consistent with an association between positive (negative) abnormal returns and increasing (decreasing) price targets $(0.3191, \mathrm{t}=9.34$, one-tailed $\mathrm{p}<0.01)$. This shows that price target revisions contain new information that is quickly impounded by the market. In fact, the market reaction for a given change in a price target forecast is stronger than that for an equal percentage change in an earnings forecast, i.e. higher coefficient, $t$ value, and a higher adjusted $\mathrm{R}^{2}$.

In column 4, we examine whether each of the three summary components of an analyst report, forecast revisions, recommendations, and price target changes, contribute information beyond what's contained in the others. When all three are included in our regression, we find that earnings forecast revisions, price target revisions, and the mean return for an upgrade remain positive and statistically significant while the mean return for a downgrade remains statistically negative. The results for price target revisions remain stronger than those of earnings forecast revisions. Including the three primary components of an analyst's report simultaneously in our regression increases the adjusted $\mathrm{R}^{2}$ to $22 \%$. Our results extend Francis and Soffer (1997), who only look at earnings forecast revisions and recommendations, and support the conjecture that the information in each of the three components of an analyst's report is not subsumed by the other two. Column 4A calculates, as column 2A did, the mean returns and $\mathrm{F}$ values for upgrades and downgrades by summing $\left(\alpha_{0}+\alpha_{2}\right)$ and $\left(\alpha_{0}+\alpha_{3}\right)$.

Regression results reported in column 5 examine the effects of the strength of an analyst's arguments and affiliations between the brokerage and the analyzed firm by adding STR_ARG and UND_HLD. We predict that the strength of arguments contained in the report is 
likely to amplify investor's reactions to both good and bad news suggesting that $\alpha_{5}$ will be positive. In cases where a brokerage may have served as an underwriter for or has current holdings in a reviewed firm, we expect investors to exhibit skepticism in responding to good news and a more pronounced reaction to bad news resulting in $\alpha_{6}$ being negative. The coefficient on STR_ARG is positive and statistically significant $(0.0080, \mathrm{t}=3.59$, one-tailed $\mathrm{p}<$ 0.01) indicating that investors react to a report's contents even in the presence of the three primary components previously discussed. However, earnings forecast revisions are now less significant $(0.0666, \mathrm{t}=1.89$, one-tailed $\mathrm{p}<0.05)$ and recommendation upgrades are no longer significant. Given information regarding the strength of an analyst's arguments as contained in a report's text and affiliation, investors appear to no longer rely on upgrade labels attached to a report and rely less on earnings forecast revisions. In contrast, downgrades remain significant and provide information in addition to the strength of arguments. Finally, we find that the coefficient for existing relationships between the analyst and company is statistically insignificant contradicting prior work $(-0.0017, \mathrm{t}=-0.25$, one-tailed $\mathrm{p}>0.10)$.

Overall, our results in Table 2 replicate the findings of prior research that earnings forecast revisions and recommendation changes are positively and significantly associated with the market's reaction at the time a security analyst report is released. More importantly, our results provide support for the hypothesis that price target changes contain information even in the presence of the other key components of an analyst report. This information is significant and is stronger than that contained in earnings forecast revisions. Finally, we demonstrate the importance of including the strength of arguments presented by an analyst in support of his recommendations.

\subsection{The effects of report type}

Prior research, the CARs in Table 1, Panel C, and column 2 of Table 2 indicate that the market reacts as predicted to changes in recommendations, i.e. positively to upgrades and negatively to downgrades. This holds even when other key summary elements, i.e. earnings forecast revisions and price target revisions are added. However, column 5 indicates that 
additional information, such as strength of arguments, affects upgrades differently from downgrades. In this section, we further investigate the effects of the information released in an analyst report by conditioning on the direction of the recommendation revision.

Current evidence on whether or not investors tend to place greater reliance on specific information in an analyst's report conditional on report type (e.g., upgrade, downgrade, or reiteration) is inconclusive. As stated earlier, Francis and Soffer (1997) find that investors place greater weight on earnings forecast revisions for favorable reports while Hirst, Koonce, and Simko (1995) find that investors are more likely to analyze other information when reports are unfavorable. Our database allows us to examine this question utilizing a broader set of information than that available to Francis and Soffer and overcomes the shortcomings associated with an experimental setting such as the one employed by Hirst, Koonce, and Simko. To investigate whether potential investors assess the information contained in security analysts' reports conditional on whether the report is an upgrade, a reiteration, or a downgrade, we estimate the following regression using ordinary least squares:

$$
\begin{aligned}
& \mathrm{CAR}_{\mathrm{j}, \mathrm{t}}=\gamma_{0}+\gamma_{1} \mathrm{EARN}_{-} \mathrm{REV} \mathrm{j}_{\mathrm{j}, \mathrm{t}}+\gamma_{2} \mathrm{UP} \_\mathrm{GR}_{\mathrm{j}, \mathrm{t}}+\gamma_{3} \mathrm{DOWN} \_\mathrm{GR}_{\mathrm{j}, \mathrm{t}}+\gamma_{4} \mathrm{TGT} \_\mathrm{REV} \mathrm{j}_{\mathrm{j}, \mathrm{t}} \\
& +\gamma_{5} \mathrm{STR} \_A R G_{\mathrm{j}, \mathrm{t}}+\gamma_{6} \mathrm{UND}_{-} \mathrm{HLD}_{\mathrm{j}, \mathrm{t}}+\gamma_{7} \mathrm{EARN}_{-} \mathrm{REV}_{\mathrm{j}, \mathrm{t}} * \mathrm{UP} \_\mathrm{GR}_{\mathrm{j}, \mathrm{t}} \\
& +\gamma_{8} \text { EARN_REV }{ }_{\mathrm{j}, \mathrm{t}} * \text { DOWN_GR } \mathrm{j}_{\mathrm{j}, \mathrm{t}}+\gamma_{9} \mathrm{TGT}_{-} \mathrm{REV}_{\mathrm{j}, \mathrm{t}} * \mathrm{UP} \_\mathrm{GR}_{\mathrm{j}, \mathrm{t}} \\
& +\gamma_{10} \mathrm{TGT}_{-} \mathrm{REV} \mathrm{j}_{\mathrm{j}, \mathrm{t}} * \text { DOWN_GR } \mathrm{j}_{\mathrm{j}, \mathrm{t}}+\gamma_{11} \mathrm{STR} \_\mathrm{ARG} \mathrm{j}_{\mathrm{j}, \mathrm{t}} * \mathrm{UP} \_\mathrm{GR}_{\mathrm{j}, \mathrm{t}} \\
& +\gamma_{12} \mathrm{STR} \_A R G_{\mathrm{j}, \mathrm{t}} * \text { DOWN_GR } \mathrm{j,t}+\gamma_{13} \mathrm{UND}_{-} \mathrm{HLD}_{\mathrm{j}, \mathrm{t}} * \mathrm{UP} \_\mathrm{GR}_{\mathrm{j}, \mathrm{t}} \\
& +\gamma_{14} \mathrm{UND}_{-} \mathrm{HLD} \mathrm{j}_{\mathrm{j}, \mathrm{t}} * \text { DOWN_GR } \mathrm{j}_{\mathrm{t}, \mathrm{t}}+\xi_{\mathrm{j}, \mathrm{t}}
\end{aligned}
$$

Equation (2) is simply equation (1) modified by the addition of eight interaction variables computed as EARN_REV*UP_GR, EARN_REV*DOWN_GR, TGT_REV*UP_GR, TGT_REV*DOWN_GR, STR_ARG*UP_GR, STR_ARG*DOWN_GR, UND_HLD*UP_GR, and UND_HLD*DOWN_GR.

The intercept, $\gamma_{0}$, represents an investor's reaction to a reiteration of a prior recommendation, controlling for all the other information found in the analyst's report. Likewise, the coefficient values on EARN_REV $\left(\gamma_{1}\right)$, TGT_REV $\left(\gamma_{4}\right), \operatorname{STR} \_\operatorname{ARG}\left(\gamma_{5}\right)$, and 
UND_HLD $\left(\gamma_{6}\right)$ represent the degree an investor reacts to earnings forecast revisions, target revisions, the strength of a report's arguments, and the affiliation of the brokerage issuing the recommendation for a reiteration.

Tests of hypotheses about how a report's type affects investor reaction are based on the upgrade (UP_GR) and downgrade (DOWN_GR) shift and differential variables. For example, a significant negative coefficient on TGT_REV*UP_GR would indicate that investors place less weight on target revisions for upgrades as related to reiterations. The mean coefficients and $\mathrm{F}$ statistics for upgrades as they relate to earnings forecast revisions, target revisions, the strength of a report's arguments and the affiliation characteristics of the brokerage issuing the recommendation are captured by $\left(\gamma_{1}+\gamma_{7}\right.$, EARN_REV + EARN_REV * UP_GR $),\left(\gamma_{4}+\gamma_{9}\right.$, TGT_REV + TGT_REV *UP_GR $),\left(\gamma_{5}+\gamma_{11}, \mathrm{STR} \_A R G+\mathrm{STR} \_A R G * U P \_G R\right)$, and $\left(\gamma_{6}+\gamma_{13}\right.$, UND_HLD + UND_HLD * UP_GR). Similarly the mean coefficients and F statistics for downgrades are given by $\left(\gamma_{1}+\gamma_{8}\right.$, EARN_REV + EARN_REV * DOWN_GR $),\left(\gamma_{4}+\gamma_{10}\right.$, TGT_REV + TGT_REV *DOWN_GR $),\left(\gamma_{5}+\gamma_{12}\right.$, STR_ARG + STR_ARG * DOWN_GR $)$, and $\left(\gamma_{6}+\gamma_{14}, \mathrm{UND} \_H L D+\mathrm{UND} \_H L D *\right.$ DOWN_GR $)$.

Table 3 reports the results from estimating equation (2) organized by recommendation revision type. We find evidence that investors assess the information contained in security analysts' reports conditional on whether the report is an upgrade, a reiteration, or a downgrade. Investors appear most interested in an analyst's supporting documentation and affiliation in the case of a downgrade. As expected, TGT_REV $\left(\gamma_{4}+\gamma_{10}=0.3841, \mathrm{~F}=13.09\right.$, one-tailed $\mathrm{p}<$ 0.01), EARN_REV $\left(\gamma_{5}+\gamma_{8}=0.1659, \mathrm{~F}=2.74\right.$, one-tailed $\left.\mathrm{p}<0.05\right)$ and STR_ARG $\left(\gamma_{3}+\gamma_{12}=\right.$ $0.0149, \mathrm{~F}=3.21$, one-tailed $\mathrm{p}<0.05)$ are all significantly positive while HLD_UND is significantly negative $\left(\gamma_{6}+\gamma_{14}=-0.0251, F=1.92\right.$, one-tailed $\left.p<0.10\right)$. In the case of reiterations, only price targets revisions $(0.1889, \mathrm{t}=4.27$, one-tailed $\mathrm{p}<0.01)$ and the strength of the arguments $(0.0102, \mathrm{t}=4.16$, one-tailed $\mathrm{p}<0.01)$ are statistically significant. Unlike downgrades, however, in reiterations investors do not appear to adjust their reaction in response 
to earnings forecast revisions $(0.0309, \mathrm{t}=0.81$, one-tailed $\mathrm{p}>0.10)$ or to an affiliation to the analyst's brokerage and the firm being analyzed $(0.0003, \mathrm{t}=0.03$, one-tailed $\mathrm{p}>0.10)$.

In contrast to the results observed for downgrades and reiterations, but consistent with Hirst, Koonce, and Simko (1995), investors do not appear to investigate beyond report type in the case of upgrades. The mean return for upgrades is large, positive, and statistically significant $\left(\gamma_{0}+\gamma_{2}=0.0936, F=7.63\right.$, one-tailed $\left.\mathrm{p}<0.01\right)$. However, the coefficient estimates for EARN_REV $\left(\gamma_{1}+\gamma_{7}=0.1132, F=0.59\right.$, one-tailed $\left.p>0.10\right), T G T \_R E V\left(\gamma_{4}+\gamma_{9}=0.0606, F=\right.$ 0.48 , one-tailed $\mathrm{p}>0.10)$, and UND_HLD $\left(\gamma_{6}+\gamma_{13}=0.0053, \mathrm{~F}=0.14\right.$, one-tailed $\left.\mathrm{p}>0.10\right)$ are all insignificant. The only anomaly of our results is that the mean return for STR_ARG upgrades is significantly negative $\left(\gamma_{5}+\gamma_{11}=-0.0117, \mathrm{~F}=3.83\right.$, one-tailed $\left.\mathrm{p}<0.05\right)$ which is the opposite of our predicted sign.

These results lead to the conclusion that investors pay closer attention to the total content of analyst reports in the case of downgrades and reiterations. This is not surprising in the case of reiterations since the recommendation level does not contain much new information. However, investors seem to read downgrade reports closely, utilizing more supporting information than in the case of upgrades. Even though other information contained in an analyst's report beyond the summary recommendation is not significant in the case of recommendation upgrades, the contents of a report are still important for reiterations and downgrades. As shown in Table 1, these two categories constitute $76.6 \%$ of all reports issued during our sample period.

\section{Price Target Accuracy}

Price targets received most of the analyst media coverage prior to the recent emphasis on recommendation levels. Headlines such as "Price Targets are Hazardous to Investors' Wealth" or "Forget Analysts' Price Targets. They're Really Just for Show" represent the content of these articles. ${ }^{18}$ Skepticism about analysts' research and the projections they produce has also

\footnotetext{
${ }^{18}$ See Morgenson (2001) and Maiello (2000).
} 
captured the attention of members of congress and the SEC (See Tully (2001)). As discussed earlier, analysts may be more likely to issue highly favorable recommendations due to concerns over personal compensation, relationships with the analyzed firms' management, or their own firm's underwriting business. Price targets may either be a way for analysts to ameliorate the effects of overly optimistic reports, or a part of the sales hype used to peddle stocks. In sections 4.1 and 4.2, we provide evidence consistent with price target changes containing important additional information used by investors. This result is especially true for reiterations and downgrades. This is proof that the market does react to price targets, the question now becomes should they? In this section, we provide some results on price target accuracy.

Our analysis uses 818 price targets issued between 1997 and 1999. Of this sample, 796 forecasts are for a price target above the current price. For this subsample, we consider a price target prediction to be accurate if the analyzed firm's stock price equals or exceeds the projected price at any time during the 12-month period following the release of a report. Most, but not all analysts, list a twelve-month time horizon for their price targets. For the remaining 22 targets that forecast price decreases, we consider an analyst to be accurate and the target achieved if the stock price falls below the price target. Table 4, Panel A, presents price target accuracy and the time necessary to achieve it categorized by the type of recommendation. For the overall sample, we find that price forecasts are achieved in $54.28 \%$ of all cases. Interestingly, price targets below the current price are achieved in 20 of the 22 instances.

Table 4, Panel B, Column 1, Target Missed, presents the average percentage of the price target achieved by the $45.5 \%$ of the firms that do not reach the analysts' price target. The ratio is the maximum price achieved within 12 months divided by the price target if the price target is set above the current price, and the price target divided by the minimum price achieved within 12 months if the price target is set below the current price. Column 3, Target Achieved, shows that firms that achieve the price target usually overshoot it by an average of $37 \%$ during the 12 months. We do not consider subsequent price target revisions that may reduce this overshooting percentage. 
Although not shown, the probability of achieving a particular target is highly dependent on the level of optimism exhibited by the analyst. Price targets that project a change of zero to ten percent and ten to twenty percent are achieved $74.42 \%$ and $59.57 \%$ of the time, respectively. In contrast, price targets that project a change in price of $70 \%$ or more are realized in less than $25 \%$ of the cases observed.

Taken together, Tables 4A and 4B show that slightly more than 50\% of the price targets are achieved. In instances where price forecasts are missed, the average maximum (minimum) price observed for projected increases (decreases) was $84 \%$ of the price target. Whether this is a good record of accuracy in a rising market is a conclusion we leave to the reader.

\section{Valuation methodology}

The methodology used in valuing stocks falls into one of three major categories; earnings or cash flow multiples, discounted cash flow (DCF) models, and asset multiples. Earnings or cash flow multiples include price to earnings (PE) ratios, relative price to earnings (Relative PE) ratios, earnings before interest and tax (EBIT) multiples, and earnings before interest, tax, deprecation, and amortization (EBITDA) multiples. DCF models use estimated discount rates and projected cash flows, and include free cash flow to the firm, free cash flow to equity, adjusted present value (APV), and enterprise value added (EVA). Asset multiples include book value, market to book value, replacement value, and liquidation value.

The first question we ask in this section is does the market react differently depending on the valuation methodology employed? We add valuation dummies to equation (1) and find that these valuation methodologies are insignificant in all our regressions ${ }^{19}$. That is, the market does not react differently depending on the valuation methodology used by the analyst or whether the analyst uses one or many. As business school professors who teach DCF as the superior

\footnotetext{
${ }^{19} \mathrm{We}$ do no report these results but they are available from the authors.
} 
valuation method, we find this result disappointing. The methodology is either being misapplied or it is not significant ${ }^{20}$.

Next, in Table 5, we examine whether the valuation methodology employed by an analyst affects the probability of achieving a particular target. Earnings multiples are not listed as a separate category since every report that lists valuation methodology, over $99 \%$ of analyst reports, use some form of PE, relative PE, or other earnings multiple. Surprisingly, we find few consistencies across recommendation types. Earnings multiples have the highest percentage of target achieved for reiterations, asset multiples the highest for upgrades, and DCF variations the highest for downgrades. (“Other” has $100 \%$ target achieved for downgrades but there are only four observations.) For all price targets the earnings multiple percentage is slightly ahead of DCF variations with asset multiples third. The only consistent performance appears to come in cases where the analyst employs a "unique" method other than an earnings multiple, a discounted cash flow model, or an asset multiple. This is usually the analyst's own methodology which is not used by other analysts or covered in most valuation textbooks. In these alternative model cases, the probability of achieving a projected target is significantly lower.

\section{Conclusion}

This paper examines the association between security returns around the release of analysts' stock reports and the content of those reports. Using a database constructed from security analyst reports issued between 1997 and 1999, we replicate the findings in prior research that earnings forecast revisions and recommendation revisions are significantly and positively associated with the market's reaction at the time a security analyst report is released. We extend the literature by providing evidence that price target changes also contain information even in the presence of these other key components.

\footnotetext{
${ }^{20}$ It is possible that a number of analysts use a DCF model to predict prices but translate this into earnings multiples for the text of their report.
} 
We find that the market reaction to price target revisions is stronger than that of an equal percentage change in earnings forecasts. We also demonstrate that the information associated with changes in earnings forecasts appears to be subsumed when proxies for the strength of an analyst's arguments and the affiliation between the brokerage and the firm being analyzed are incorporated.

Next, we examine whether investors assess the information contained in security analysts' reports conditional on whether the report is an upgrade, a reiteration, or a downgrade. We find that investors place greater reliance on the content of security analyst reports when they are reiterations or downgrades. In these instances, the strength of an analyst's arguments or the price target revision account for a significant proportion of the observed market reaction.

Finally, we provide an examination of the accuracy of price targets and the importance of valuation methodology. We find that approximately $54 \%$ of analysts' price targets are achieved within 12 months. When the target is missed, the average maximum (minimum) price observed for projected increases (decreases) was $84 \%$ of the price target. We fail to observe any systematic association between the valuation method employed by an analyst and either the market's reaction or the probability of achieving a price target. 


\section{REFERENCES}

Abdel-khalik, A. and B. Ajinkya. "Returns to Informational Advantages: The Case of Analysts' Forecast Revisions." The Accounting Review Vol. 57, No. 3 (1982): 661-80.

Barber, B., R. Lehavy, M. McNichols, and B. Trueman. "Can Investors Profit from the Profits? Security Analyst Recommendations and Stock Returns." The Journal of Finance 56 (2001): 531-563.

Beneish, M. "Stock Prices and the Dissemination of Analysts' Recommendations." Journal of Business Vol. 64, no. 3 (1991): 393-416.

Bjerring, J., J. Lakonishok, and T. Vermaelen. "Stock Prices and Financial Analysts' Recommendations.” Journal of Finance Vol. 38, no. 1 (1983): 187-204.

Bradshaw, M. “Analysts' Reports, Stock Recommendations, and Target Prices.” Working Paper, 2001, Harvard University.

Brav, A. and R. Lehavy. “An Empirical Analysis of Analysts’ Target Prices: Short Term Informativeness and Long Term Dynamics." Working Paper, 2001, UC Berkeley and Duke University.

Elton, E., M. Gruber, and S. Grossman. "Discrete Expectational Data and Portfolio Performance.” Journal of Finance (1986): 699-713.

Francis, J. and L. Soffer. "The Relative Informativeness of Analysts' Stock Recommendations and Earnings Forecast Revisions." Journal of Accounting Research Vol. 35, no. 2 (1997): 193-211.

Hirst, E., L. Koonce and P. Simko. "Investor Reactions to Financial Analysts' Research Reports." Journal of Accounting Research Vol. 33, no. 2 (1995): 335-351.

Liu, P., Smith, S., and Syed, A. "Stock Price Reactions to the Wall Street Journal's Securities Recommendations." Journal of Financial and Quantitative Analysis (1990): 399-410.

Lloyd Davies, P. and M. Canes. "Stock Prices and the Publication of Second-Hand Information." Journal of Business Vol. 51, no. 1 (1978): 43-56.

Lys, T. and S. Sohn. “The Association Between Revisions of Financial Analysts' Earnings Forecasts and Security Price Changes." Journal of Accounting and Economics 13 (1990): 341-363.

Maiello, M. "Moving Targets: Forget analysts' price targets. They're really just for show." Forbes (December 11, 2000): 288-290. 
"Merrill Lynch Announces Major Changes to Stock Ratings and Compensation System for Research Analysts." BusinessWire (June 7, 2002).

Michaely, R. and K. Womack. "Conflict of Interest and the Credibility of Underwriter Analyst Recommendations." The Review of Financial Studies Vol. 12, no. 4 (1999): 653-686.

Mikhail, B., B. Walther and R. Willis. "Do Security Analysts Exhibit Persistent Differences in Stock Picking Ability?" Duke University and Northwestern University Working Paper (2002).

Morgenson, G. "Price Targets are Hazardous to Investors' Wealth." The New York Times (August 5, 2001): 3.1.

Opdyke, J. "Should You Trust Wall Street's New Ratings?" The Wall Street Journal (July 17, 2002): D1, D2.

Santoli, M. "The Whole Truth: It's Time to Repair Wall Street's Dubious Research Machine." Barron's (May 28, 2001): 23.

"SEC Approves New Rules for Research Analysts." Securities Litigation and Regulation Reporter (May 22, 2002).

Stickel, S. "Common Stock Returns Surrounding Earnings Forecast Revisions: More Puzzling Evidence." The Accounting Review Vol. 66, No. 2 (1991): 402-416.

Stickel, S. "Reputation and Performance Among Security Analysts." The Journal of Finance 47 (1992): 1811-1836.

Stickel, S. "The Anatomy of the Performance of Buy and Sell Recommendations." Financial Analysts Journal 51 (1995): 25-39.

Stone, A. "One Way to End the Analyst Scandals.” BusinessWeek Online (April 25, 2002)

Taylor, P. “Don’t Shoot the Analysts.” National Post (February 22, 2002): FP15.

Tsao, A. "When a Stock's Rating and Target Collide." BusinessWeek Online (April 25, 2002).

Tully, S., "Is Wall Street Serious About Reform? Slammed By The Public, The Press, And Now Even Congress, The Big Investment Firms Have Promised To Change The Way They Do Business. Their Lobbying Efforts Tell A Different Story," Fortune (July 9, 2001), p. 90.

Womack, K. “Do Brokerage Analysts' Recommendations Have Investment Value?" The Journal of Finance 51 (1996): 137-16. 
TABLE 1: Panel A

Security Analyst Report Descriptive Statistics

Percentages of Reports Containing Selected Data Organized by Type of Recommendation

\begin{tabular}{|c|c|c|c|c|c|c|c|c|c|c|c|c|c|c|c|}
\hline & \multicolumn{2}{|c|}{ Strong Buy } & \multicolumn{3}{|c|}{ Buy } & \multicolumn{3}{|c|}{ Hold } & \multicolumn{2}{|c|}{ Sell } & \multirow{2}{*}{$\begin{array}{c}\text { S_Sell } \\
\text { Down }\end{array}$} & \multicolumn{3}{|c|}{ All } & \multirow{2}{*}{$\begin{array}{l}\text { Total } \\
\text { Sample }\end{array}$} \\
\hline & Up & Reit & Up & Reit & Down & Up & Reit & Down & Reit & Down & & Up & Reit & Down & \\
\hline Number of Reports & 149 & 198 & 111 & 296 & 43 & 2 & 244 & 77 & 1 & 3 & 2 & 262 & 739 & 125 & 1126 \\
\hline$\%$ of Sample & 13.2 & 17.6 & 9.9 & 26.3 & 3.8 & 0.2 & 21.7 & 6.8 & 0.0 & 0.3 & 0.2 & 23.3 & 65.5 & 11.1 & 100.0 \\
\hline \multicolumn{16}{|l|}{ Earnings Forecast } \\
\hline 1 Year & 97.3 & 100.0 & 99.1 & 99.0 & 97.7 & 100.0 & 99.6 & 98.7 & 100.0 & 100.0 & 100.0 & 98.1 & 99.5 & 98.4 & 99.1 \\
\hline Multiple Years & 95.3 & 96.5 & 95.5 & 95.6 & 93.0 & 100.0 & 95.9 & 89.6 & 100.0 & 100.0 & 100.0 & 95.4 & 95.9 & 91.2 & 95.3 \\
\hline \multicolumn{16}{|l|}{ Price Targets } \\
\hline Target Reported & 94.0 & 94.4 & 98.2 & 91.2 & 95.3 & 100.0 & 11.1 & 50.6 & 100.0 & 0.0 & 100.0 & 95.8 & 65.5 & 65.6 & 72.6 \\
\hline Point Estimate Provided & 88.6 & 95.7 & 90.7 & 97.4 & 80.5 & 100.0 & 96.3 & 92.3 & 100.0 & NA & 50.0 & 89.2 & 96.9 & 85.4 & 93.8 \\
\hline Projected Increase & 34.6 & 44.0 & 22.6 & 34.3 & 21.0 & -17.5 & 8.6 & 5.5 & -9.6 & NA & -19.0 & 28.9 & 36.6 & 19.1 & 32.9 \\
\hline \multicolumn{16}{|l|}{ Forecasts } \\
\hline Income Statement & 55.6 & 24.7 & 35.1 & 13.5 & 39.5 & 0.0 & 24.6 & 39.0 & 0.0 & 33.3 & 100.0 & 46.6 & 20.1 & 40.0 & 28.5 \\
\hline Balance Sheet & 12.1 & 3.5 & 9.0 & 2.7 & 2.3 & 0.0 & 2.0 & 10.3 & 0.0 & 33.3 & 0.0 & 10.7 & 2.7 & 8.0 & 5.1 \\
\hline Cash flow Statement & 30.9 & 14.6 & 27.9 & 9.8 & 20.9 & 0.0 & 8.6 & 33.8 & 0.0 & 0.0 & 100.0 & 29.4 & 10.7 & 29.6 & 17.1 \\
\hline \multicolumn{16}{|l|}{ Segment Data } \\
\hline Geographic & 4.7 & 3.5 & 3.6 & 6.1 & 0.0 & 0.0 & 1.2 & 2.6 & 0.0 & 0.0 & 0.0 & 4.2 & 3.8 & 1.6 & 3.6 \\
\hline Product & 4.0 & 2.0 & 6.6 & 4.7 & 4.7 & 0.0 & 4.5 & 3.9 & 0.0 & 0.0 & 0.0 & 5.0 & 3.9 & 4.0 & 4.2 \\
\hline Division & 9.4 & 13.6 & 12.6 & 9.5 & 14.0 & 0.0 & 7.8 & 6.5 & 0.0 & 0.0 & 0.0 & 10.7 & 10.0 & 8.8 & 10.0 \\
\hline \multicolumn{16}{|l|}{ Affiliation } \\
\hline Underwriter & 60.8 & 64.6 & 44.1 & 53.7 & 60.5 & 0.0 & 43.4 & 39.0 & 100.0 & 66.7 & 0.0 & 53.3 & 53.4 & 46.4 & 52.6 \\
\hline Holdings & 63.5 & 88.4 & 74.8 & 91.9 & 81.4 & 50.0 & 99.6 & 51.9 & 0.0 & 66.7 & 100.0 & 68.2 & 93.4 & 63.2 & 84.2 \\
\hline \multicolumn{16}{|l|}{ Valuation Models } \\
\hline Earnings Multiples & 99.3 & 99.5 & 99.1 & 98.0 & 100.0 & 100.0 & 100.0 & 100.0 & 0.0 & 100.0 & 100.0 & 99.2 & 98.9 & 100.0 & 99.1 \\
\hline DCF Variations & 16.8 & 13.1 & 9.9 & 9.5 & 14.0 & 0.0 & 11.5 & 26.0 & 0.0 & 0.0 & 0.0 & 13.7 & 11.1 & 20.8 & 12.8 \\
\hline Asset Multiples & 23.5 & 22.7 & 22.5 & 26.3 & 14.0 & 0.0 & 32.8 & 14.3 & 0.0 & 33.3 & 50.0 & 22.9 & 27.6 & 15.2 & 25.1 \\
\hline Other & 3.4 & 6.6 & 2.7 & 3.7 & 2.3 & 0.0 & 1.2 & 5.2 & 0.0 & 0.0 & 0.0 & 3.1 & 3.6 & 4.0 & 3.5 \\
\hline Average Number Pages & 9.5 & 5.7 & 9.0 & 5.3 & 5.9 & 2.0 & 4.5 & 7.5 & 1.0 & 6.7 & 11.5 & 9.3 & 5.1 & 7.0 & 6.3 \\
\hline
\end{tabular}


TABLE 1: Panel B

Security Analyst Report Descriptive Statistics

Percentages of Reports Containing Selected Data Organized by Type of Recommendation

\begin{tabular}{|c|c|c|c|c|c|c|c|c|c|c|c|c|c|c|c|}
\hline & \multicolumn{2}{|c|}{ Strong Buy } & \multicolumn{3}{|c|}{ Buy } & \multicolumn{3}{|c|}{ Hold } & \multicolumn{2}{|c|}{ Sell } & \multirow{2}{*}{$\begin{array}{l}\text { S_Sell } \\
\text { Down }\end{array}$} & \multicolumn{3}{|c|}{ All } & \multirow{2}{*}{$\begin{array}{l}\text { Total } \\
\text { Sample }\end{array}$} \\
\hline & $\mathrm{Up}$ & Reit & Up & Reit & Down & Up & Reit & Down & Reit & Down & & Up & Reit & Down & \\
\hline \multicolumn{16}{|l|}{ Recommendation Basis } \\
\hline Stock Undervalued & 100.0 & 71.2 & 100.0 & 3.0 & 7.0 & 0.0 & 14.7 & 1.3 & 0.0 & 0.0 & 0.0 & 99.2 & 25.3 & 3.2 & 40.0 \\
\hline Stock Overvalued & 0.0 & 0.0 & 0.0 & 2.0 & 2.3 & 0.0 & 0.8 & 9.1 & 0.0 & 100.0 & 100.0 & 0.0 & 1.1 & 10.4 & 1.9 \\
\hline Relatively Undervalued & 100.0 & 69.7 & 100.0 & 7.4 & 11.6 & 0.0 & 4.5 & 7.8 & 0.0 & 0.0 & 0.0 & 99.2 & 23.2 & 8.8 & 39.3 \\
\hline Relatively Overvalued & 0.0 & 2.0 & 0.0 & 1.4 & 6.7 & 0.0 & 7.4 & 9.1 & 100.0 & 100.0 & 100.0 & 0.0 & 3.6 & 12.0 & 3.7 \\
\hline Revenues (Inc) & 39.6 & 46.0 & 36.9 & 64.5 & 11.6 & 0.0 & 6.6 & 13.0 & 100.0 & 0.0 & 0.0 & 38.2 & 40.4 & 12.0 & 36.7 \\
\hline Revenues (Dec) & 0.0 & 1.5 & 3.6 & 1.4 & 9.3 & 0.0 & 4.5 & 40.3 & 0.0 & 0.0 & 0.0 & 1.5 & 2.4 & 28.0 & 5.0 \\
\hline Earnings (Inc) & 62.4 & 42.9 & 54.1 & 24.3 & 23.3 & 0.0 & 5.3 & 9.1 & 0.0 & 0.0 & 0.0 & 58.4 & 23.0 & 13.6 & 30.2 \\
\hline Earnings (Dec) & 0.0 & 0.0 & 3.6 & 5.1 & 23.3 & 0.0 & 6.6 & 19.5 & 0.0 & 100.0 & 0.0 & 1.5 & 4.2 & 22.4 & 5.6 \\
\hline Product Intro (Pos) & 26.2 & 17.2 & 18.0 & 20.9 & 7.0 & 0.0 & 8.6 & 3.9 & 0.0 & 0.0 & 0.0 & 22.5 & 15.8 & 4.8 & 16.1 \\
\hline Product Intro (Neg) & 0.0 & 0.5 & 0.9 & 1.4 & 2.3 & 0.0 & 0.0 & 3.9 & 0.0 & 0.0 & 0.0 & 0.4 & 0.7 & 3.2 & 0.9 \\
\hline New Projects (Pos) & 13.4 & 9.6 & 8.1 & 12.8 & 7.0 & 0.0 & 10.7 & 10.4 & 0.0 & 0.0 & 0.0 & 11.1 & 11.4 & 8.8 & 11.0 \\
\hline New Projects (Neg) & 0.0 & 0.0 & 0.9 & 1.0 & 2.3 & 0.0 & 1.2 & 2.6 & 0.0 & 0.0 & 0.0 & 0.4 & 0.8 & 2.4 & 0.9 \\
\hline Cost Efficiencies & 39.6 & 21.2 & 24.3 & 15.2 & 11.6 & 50.0 & 19.7 & 13.0 & 0.0 & 0.0 & 50.0 & 33.2 & 18.5 & 12.8 & 21.3 \\
\hline Cost Inefficiencies & 2.0 & 7.6 & 10.8 & 18.9 & 11.6 & 0.0 & 12.7 & 19.5 & 0.0 & 33.3 & 0.0 & 5.7 .0 & 13.8 & 16.8 & 12.2 \\
\hline Expectations Met & 37.6 & 29.3 & 10.8 & 33.1 & 30.2 & 0.0 & 37.3 & 31.2 & 0.0 & 0.0 & 100.0 & 26.0 & 33.5 & 31.2 & 31.5 \\
\hline Expectations Not Met & 9.4 & 7.1 & 29.7 & 7.8 & 18.6 & 0.0 & 11.9 & 19.5 & 0.0 & 66.7 & 0.0 & 17.9 & 8.9 & 20.0 & 12.2 \\
\hline M\&A Activity (Pos) & 28.9 & 10.6 & 21.6 & 13.5 & 18.6 & 0.0 & 6.6 & 9.1 & 0.0 & 0.0 & 0.0 & 25.6 & 10.4 & 12.0 & 14.1 \\
\hline M\&A Activity (Neg) & 0.0 & 0.5 & 1.8 & 0.3 & 2.3 & 0.0 & 2.5 & 7.8 & 0.0 & 0.0 & 0.0 & 0.8 & 1.1 & 5.6 & 1.5 \\
\hline Repurchases (Pos) & 17.4 & 7.1 & 14.4 & 9.1 & 7.0 & 50.0 & 17.6 & 14.3 & 0.0 & 0.0 & 0.0 & 16.4 & 11.4 & 11.2 & 12.5 \\
\hline Repurchases (Neg) & 0.0 & 0.0 & 0.9 & 0.3 & 0.0 & 0.0 & 0.0 & 3.9 & 0.0 & 0.0 & 0.0 & 0.4 & 0.1 & 2.4 & 0.4 \\
\hline Industry Climate (Pos) & 24.2 & 12.1 & 18.9 & 11.1 & 9.3 & 50.0 & 4.5 & 3.9 & 0.0 & 0.0 & 0.0 & 22.1 & 9.2 & 5.6 & 11.8 \\
\hline Industry Climate (Neg) & 3.4 & 7.1 & 8.1 & 5.1 & 7.0 & 0.0 & 7.4 & 15.6 & 0.0 & 66.7 & 50.0 & 5.3 & 6.5 & 14.4 & 7.1 \\
\hline Management (Pos) & 37.6 & 15.7 & 25.2 & 27.4 & 7.0 & 50.0 & 4.1 & 22.1 & 0.0 & 0.0 & 50.0 & 32.4 & 16.6 & 16.8 & 20.3 \\
\hline Management (Neg) & 0.0 & 1.0 & 0.0 & 0.7 & 7.0 & 0.0 & 1.6 & 7.8 & 0.0 & 66.7 & 50.0 & 0.0 & 1.1 & 9.6 & 1.8 \\
\hline International Ops (Pos) & 19.5 & 9.6 & 11.7 & 32.1 & 4.7 & 0.0 & 5.3 & 0.0 & 0.0 & 0.0 & 0.0 & 16.0 & 17.2 & 1.6 & 15.2 \\
\hline International Ops (Neg) & 2.7 & 1.0 & 2.7 & 2.0 & 9.3 & 0.0 & 7.0 & 15.6 & 0.0 & 33.3 & 0.0 & 2.7 & 3.4 & 13.6 & 4.4 \\
\hline Leverage (Pos) & 11.4 & 4.0 & 4.5 & 7.4 & 7.0 & 0.0 & 2.5 & 3.9 & 0.0 & 0.0 & 0.0 & 8.4 & 4.9 & 4.8 & 5.7 \\
\hline Leverage (Neg) & 4.7 & 2.5 & 0.9 & 3.7 & 2.3 & 0.0 & 7.4 & 10.4 & 0.0 & 33.3 & 0.0 & 3.1 & 4.7 & 8.0 & 4.7 \\
\hline Competition (Pos) & 15.4 & 6.6 & 3.6 & 17.9 & 4.7 & 0.0 & 2.5 & 7.8 & 0.0 & 0.0 & 0.0 & 10.3 & 9.9 & 6.4 & 9.6 \\
\hline Competition (Neg) & 4.0 & 4.0 & 3.6 & 2.4 & 7.0 & 50.0 & 9.4 & 10.4 & 0.0 & 33.3 & 0.0 & 4.2 & 5.1 & 9.6 & 5.4 \\
\hline Risk (Pos) & 17.4 & 8.6 & 2.7 & 6.8 & 11.6 & 0.0 & 0.8 & 6.5 & 0.0 & 0.0 & 0.0 & 11.1 & 5.3 & 8.0 & 6.9 \\
\hline Risk (Neg) & 7.4 & 4.0 & 2.7 & 5.7 & 7.0 & 0.0 & 4.9 & 20.8 & 0.0 & 66.7 & 50.0 & 5.3 & 5.0 & 17.6 & 6.5 \\
\hline
\end{tabular}


TABLE 1: Panel C

\section{Security Analyst Report Descriptive Statistics}

Model Variables

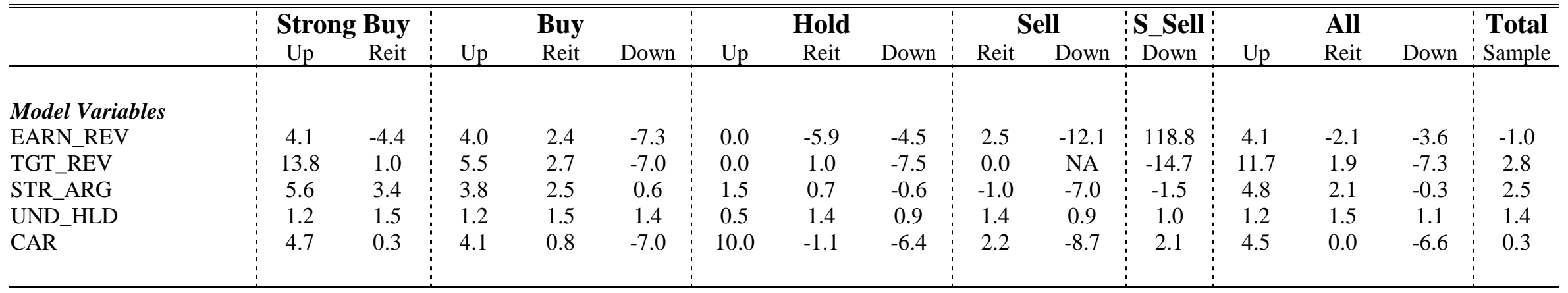

Notes to table 1: All numbers presented are percentages unless otherwise noted. The estimates for the model variables, EARN_REV, TGT_REV, STR_ARG, UND_HLD, and CAR are means of the respective variables not percentages. They are defined as follows: EARN_REV $\mathrm{j}_{\mathrm{j}, \mathrm{t}}=$ percentage change in the analyst's projected earnings forecast for firm $j$ at time $t$ computed as [(earnings forecast at time $t /$ earnings forecast at time $t-1)-1$ ]; TGT_REV $\mathrm{j}_{\mathrm{j}, \mathrm{t}}=$ percentage change in the analyst's projected price target for firm $\mathrm{j}$ at time $\mathrm{t}$ computed as [(price target at time $\mathrm{t} /$ price target at time $\mathrm{t}-1)-1$ ]; $\mathrm{STR} \_\mathrm{ARG}_{\mathrm{j}, \mathrm{t}}=$ a variable computed by aggregating the number of positive remarks less the number of negative remarks related to 16 specific criteria: value, relative value, sales growth, earnings growth, new product introductions, new projects, cost efficiencies, expectations met, mergers and acquisitions, repurchase programs, industry climate, management, international operations, leverage, competition, and risk; $\mathrm{UND}_{-} \mathrm{HLD}_{\mathrm{j}, \mathrm{t}}=\mathrm{a}$ variable taking on the value 0 if no relationship between the analyst's brokerage and the firm exists, 1 if the brokerage is an underwriter of the firm or has current holdings in the firm, and 2 if the brokerage is both an underwriter and has current holdings; and $\mathrm{CAR}_{\mathrm{j}, \mathrm{t}}=$ five-day market adjusted cumulative abnormal return for firm $\mathrm{j}$ centered on the report release date $\mathrm{t}$. 
TABLE 2

The Market's Reaction to the Release of a Security Analyst Report: Regression Results on Earnings forecast revisions, Recommendations, Price Target Revisions, Argument Strength, and Affiliation

\begin{tabular}{|c|c|c|c|c|c|c|c|c|c|}
\hline Variable & $\begin{array}{c}\text { Predicted } \\
\text { Sign }\end{array}$ & (1) & (2) & $(2 \mathrm{~A})$ & (3) & $(4)$ & $(4 \mathrm{~A})$ & $(5)$ & $(5 \mathrm{~A})$ \\
\hline INTERCEPT & $?$ & $\begin{array}{r}-0.0029 \\
(-0.78)\end{array}$ & $\begin{array}{r}-0.0044 \\
(-1.12)\end{array}$ & & $\begin{array}{r}-0.0018 \\
(-0.40)\end{array}$ & $\begin{array}{r}-0.0009 \\
(-0.18)\end{array}$ & & $\begin{array}{r}-0.0120 \\
(-1.57)\end{array}$ & \\
\hline EARN_REV & + & $\begin{array}{c}0.0545 * * * \\
(2.81)\end{array}$ & & & & $\begin{array}{c}0.0804 * * \\
\quad(2.27)\end{array}$ & & $\begin{array}{c}0.0666^{* *} \\
(1.89)\end{array}$ & \\
\hline UP_GR & + & & $\begin{array}{c}0.0517 * * * \\
(6.40)\end{array}$ & & & $\begin{array}{c}0.0283 \text { ** } \\
(2.24)\end{array}$ & & $\begin{array}{r}0.0123 \\
(0.92)\end{array}$ & \\
\hline DOWN_GR & - & & $\begin{array}{c}-0.0850 \text { *** } \\
(-7.31)\end{array}$ & & & $\begin{array}{c}-0.0494 * * * \\
(-3.09)\end{array}$ & & $\begin{array}{c}-0.0321 \\
(-1.93)\end{array}$ & \\
\hline Upgrade $\left(\alpha_{0}+\alpha_{2}\right)$ & + & & & $\begin{array}{c}0.0473 * * * \\
(44.84)\end{array}$ & & & $\begin{array}{c}0.0274^{* *} \\
(5.52)\end{array}$ & & $\begin{array}{r}-0.0076 \\
(0.20)\end{array}$ \\
\hline Downgrade $\left(\alpha_{0}+\alpha_{3}\right)$ & - & & & $\begin{array}{c}-0.0894 * * * \\
(66.77)\end{array}$ & & & $\begin{array}{c}-0.0503 * * * \\
(11.09)\end{array}$ & & $\begin{array}{c}-0.0520 * * * \\
(9.38)\end{array}$ \\
\hline TGT_REV & + & & & & $\begin{array}{l}0.3191 * * * \\
(9.34)\end{array}$ & $\begin{array}{c}0.2552 \text { *** } \\
\quad(7.06)\end{array}$ & & $\begin{array}{c}0.2213 \text { *** } \\
(5.99)\end{array}$ & \\
\hline STR_ARG & + & & & & & & & $\begin{array}{c}0.0080 \text { *** } \\
(3.59)\end{array}$ & \\
\hline UND_HLD & - & & & & & & & $\begin{array}{r}-0.0017 \\
(-0.25)\end{array}$ & \\
\hline Adjusted $\mathrm{R}^{2}$ & & $\begin{array}{l}0.0112 * * * \\
\quad(7.91)\end{array}$ & $\begin{array}{c}0.1382 \text { *** } \\
(56.40)\end{array}$ & & $\begin{array}{c}0.1799 * * * \\
(87.21)\end{array}$ & $\begin{array}{c}0.2193 * * * \\
(28.38)\end{array}$ & & $\begin{array}{c}0.2408 \text { *** } \\
(21.62)\end{array}$ & \\
\hline $\mathrm{N}$ & & 612 & 691 & & 393 & 390 & & 390 & \\
\hline
\end{tabular}


Notes to table 2: This table presents the results of estimating the following regression using ordinary least squares: $\mathrm{CAR}_{\mathrm{j}, \mathrm{t}}=\alpha_{0}+\alpha_{1} \mathrm{EARN}_{-} \mathrm{REV}_{\mathrm{j}, \mathrm{t}}+\alpha_{2} \mathrm{UP}_{-} \mathrm{GR}_{\mathrm{j}, \mathrm{t}}+$

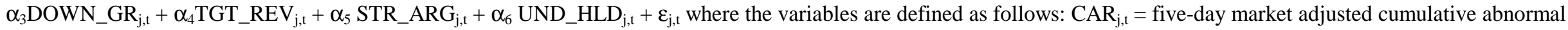

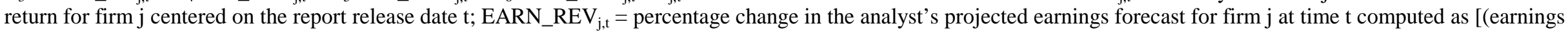

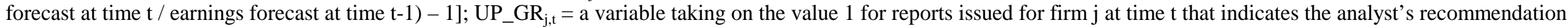

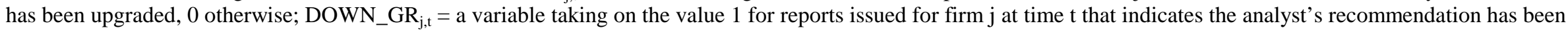

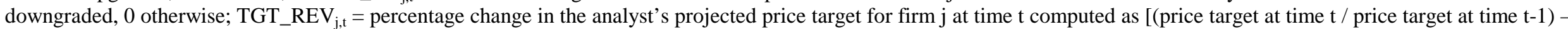

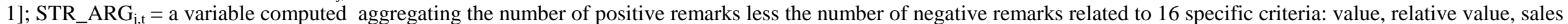
growth, earnings growth, new product introductions, new projects, cost efficiencies, expectations met, mergers and acquisitions, repurchase programs, industry climate,

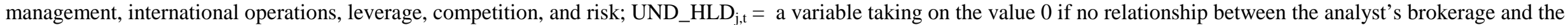

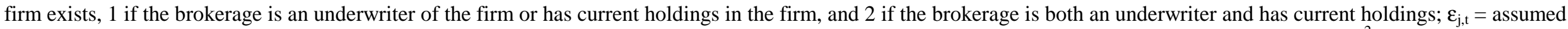

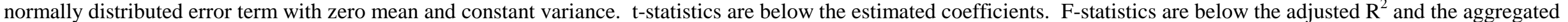

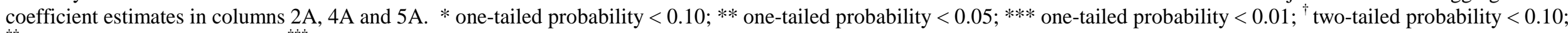
${ }^{\dagger}$ two-tailed probability $<0.05 ;{ }^{\dagger \dagger}$ two-tailed probability $<0.01$. 
TABLE 3

The Market Reaction to the Release of a Security Analyst Report:

The Effects of Recommendation Revision Type

\begin{tabular}{|c|c|c|c|c|c|c|c|c|c|c|c|c|c|c|c|}
\hline \multirow[b]{2}{*}{ Variable } & \multicolumn{5}{|c|}{ Reiterations } & \multicolumn{5}{|c|}{ Upgrades } & \multicolumn{5}{|c|}{ Downgrades } \\
\hline & $\begin{array}{c}\text { Predicted } \\
\text { Sign } \\
\end{array}$ & & Coefficient & & t-stat & $\begin{array}{c}\text { Predicted } \\
\text { Sign } \\
\end{array}$ & & oefficient & & F-stat & $\begin{array}{c}\text { Predicted } \\
\text { Sign } \\
\end{array}$ & & Joefficient & & F-stat \\
\hline Intercept & $?$ & $\gamma_{0}$ & -0.0284 & $\dagger$ & $(-1.86)$ & & & & & & & & & & \\
\hline Upgrade & & & & & & + & $\gamma_{0}+\gamma_{2}$ & 0.0936 & $* * *$ & $(7.63)$ & & & & & \\
\hline Downgrade & & & & & & & & & & & - & $\gamma_{0}+\gamma_{3}$ & 0.0008 & & $(0.00)$ \\
\hline EARN_REV & + & $\gamma_{1}$ & 0.0309 & & $(0.81)$ & + & $\gamma_{1}+\gamma_{7}$ & 0.1132 & & $(0.59)$ & + & $\gamma_{1}+\gamma_{8}$ & 0.1659 & $* *$ & $(2.74)$ \\
\hline TGT_REV & + & $\gamma_{4}$ & 0.1889 & $* * *$ & $(4.27)$ & + & $\gamma_{4}+\gamma_{9}$ & 0.0600 & & $(0.48)$ & + & $\gamma_{4}+\gamma_{10}$ & 0.3841 & $* * *$ & (13.09) \\
\hline STR_ARG & + & $\gamma_{5}$ & 0.0102 & $* * *$ & $(4.16)$ & + & $\gamma_{5}+\gamma_{11}$ & -0.0117 & $* *$ & $(3.83)$ & + & $\gamma_{5}+\gamma_{12}$ & 0.0149 & $* *$ & $(3.21)$ \\
\hline UND_HLD & - & $\gamma_{6}$ & 0.0003 & & $(0.03)$ & - & $\gamma_{6}+\gamma_{13}$ & 0.0053 & & $(0.14)$ & - & $\gamma_{6}+\gamma_{14}$ & -0.0251 & $*$ & $(1.92)$ \\
\hline
\end{tabular}

$\begin{array}{lc}\text { Adjusted } \mathrm{R}^{2} & 0.2847 \\ \text { F-stat } & (12.09) \\ \mathrm{N} & 390\end{array}$

Notes to table 3: This table presents the results of estimating the following regression using ordinary least squares: $\mathrm{CAR}_{\mathrm{j}, \mathrm{t}}=\gamma_{0}+\gamma_{1} \mathrm{EARN}_{-} \mathrm{REV}_{\mathrm{j}, \mathrm{t}}+\gamma_{2} \mathrm{UP}_{-} \mathrm{GR}_{\mathrm{j}, \mathrm{t}}+\gamma_{3} \mathrm{DOWN} \mathrm{GR}_{\mathrm{j}, \mathrm{t}}+$

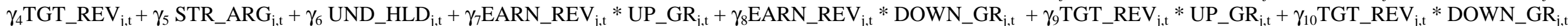
$+\gamma_{11} \mathrm{STR}_{-} A \mathrm{ARG}_{\mathrm{j}, \mathrm{t}} * \mathrm{UP}_{-} \mathrm{GR}_{\mathrm{j}, \mathrm{t}}+\gamma_{12} \mathrm{STR} \_\mathrm{ARG} \mathrm{j}_{\mathrm{j}, \mathrm{t}} * \mathrm{DOWN}_{-} \mathrm{GR}_{\mathrm{j}, \mathrm{t}}+\gamma_{13} \mathrm{UND}_{-} \mathrm{HLD}_{\mathrm{j}, \mathrm{t}} * \mathrm{UP}_{-} \mathrm{GR}_{\mathrm{j}, \mathrm{t}}+\gamma_{14} \mathrm{UND}_{-} \mathrm{HLD}_{\mathrm{j}, \mathrm{t}} *$ DOWN_GR $\mathrm{j,t}+\xi_{\mathrm{j}, \mathrm{t}}$. See notes to table 2 for variable definitions. $\mathrm{t}$-statistics are to the right of the estimated reiteration coefficients. F-statistics are to the right of the aggregated coefficient estimates for upgrades and downgrades. The adjusted

$\mathrm{R}^{2}$ and associated F-statistic is for the entire regression in equation $2 . *$ one-tailed probability $<0.10$; $* *$ one-tailed probability $<0.05$; $* * *$ one-tailed probability $<0.01$;

${ }^{\dagger}$ two-tailed probability $<0.10 ;{ }^{\dagger \dagger}$ two-tailed probability $<0.05 ;{ }^{\dagger \dagger \dagger}$ two-tailed probability $<0.01$. 
TABLE 4: Panel A

Percentage of Reports Achieving 12-Month Price Targets by Recommendation Type

\begin{tabular}{|c|c|c|c|c|c|c|}
\hline & & & Target A & eved In: & & \\
\hline & $\begin{array}{c}\text { Target } \\
\text { Achieved }\end{array}$ & $\begin{array}{c}1 \text { to } 3 \\
\text { Months }\end{array}$ & $\begin{array}{c}4 \text { to } 6 \\
\text { Months }\end{array}$ & $\begin{array}{c}7 \text { to } 9 \\
\text { Months }\end{array}$ & $\begin{array}{l}10 \text { to } 12 \\
\text { Months }\end{array}$ & $\mathrm{N}$ \\
\hline All & 54.28 & 30.81 & 13.21 & 5.62 & 4.64 & 818 \\
\hline Upgrades & 57.37 & 25.50 & 17.13 & 7.17 & 7.57 & 251 \\
\hline Reiterations & 50.72 & 30.93 & 11.55 & 5.15 & 3.09 & 485 \\
\hline Downgrades & 65.85 & 46.34 & 10.98 & 3.66 & 4.88 & 82 \\
\hline Strong Buy & 45.12 & 17.99 & 17.07 & 4.57 & 5.49 & 328 \\
\hline Upgrades & 50.00 & 16.43 & 20.00 & 7.14 & 6.43 & 140 \\
\hline Reiterations & 41.49 & 19.15 & 14.89 & 2.66 & 4.79 & 188 \\
\hline Buy & 57.14 & 35.48 & 11.67 & 7.38 & 2.62 & 420 \\
\hline Upgrades & 66.97 & 36.70 & 13.76 & 11.93 & 4.59 & 109 \\
\hline Reiterations & 54.81 & 36.67 & 10.00 & 6.30 & 1.85 & 270 \\
\hline Downgrades & 46.34 & 24.39 & 17.07 & 2.44 & 2.44 & 41 \\
\hline Hold & 77.61 & 61.2 & 4.48 & 7.46 & 4.48 & 67 \\
\hline Upgrades & 50.00 & 50.00 & 0.00 & 0.00 & 0.00 & 2 \\
\hline Reiterations & 73.08 & 53.85 & 3.85 & 11.54 & 3.85 & 26 \\
\hline Downgrades & 84.62 & 69.23 & 5.13 & 5.13 & 5.13 & 39 \\
\hline Sell & 100.00 & 100.00 & 0.00 & 0.00 & 0.00 & 1 \\
\hline Reiterations & 100.00 & 100.00 & 0.00 & 0.00 & 0.00 & 1 \\
\hline Strong Sell & 100.00 & 50.00 & 0.00 & 0.00 & 50.00 & 2 \\
\hline Downgrades & 100.00 & 50.00 & 0.00 & 0.00 & 50.00 & 2 \\
\hline
\end{tabular}


TABLE 4: Panel B

12-Month Price Maximums / Minimums and Predicted Price Targets (\%)

\begin{tabular}{lcccccc}
\hline \hline & $\begin{array}{c}\text { Target } \\
\text { Missed }\end{array}$ & N & $\begin{array}{c}\text { Target } \\
\text { Achieved }\end{array}$ & N & $\begin{array}{c}\text { Full } \\
\text { Sample }\end{array}$ & N \\
\hline All & $\mathbf{8 4 . 3 8}$ & $\mathbf{3 7 4}$ & $\mathbf{1 3 7 . 2 7}$ & $\mathbf{4 4 4}$ & $\mathbf{1 1 3 . 0 9}$ & $\mathbf{8 1 8}$ \\
Upgrades & 88.05 & 107 & 130.86 & 144 & 112.61 & 251 \\
Reiterations & 82.50 & 239 & 140.07 & 246 & 111.70 & 485 \\
Downgrades & 86.37 & 28 & 141.59 & 54 & 122.74 & 82 \\
Strong Buy & $\mathbf{8 3 . 2 0}$ & $\mathbf{1 8 1}$ & $\mathbf{1 2 9 . 3 0}$ & $\mathbf{1 4 7}$ & $\mathbf{1 0 3 . 8 6}$ & $\mathbf{3 2 8}$ \\
Upgrades & 87.20 & 71 & 127.53 & 69 & 107.08 & 140 \\
Reiterations & 80.61 & 110 & 130.86 & 78 & 101.46 & 188 \\
Buy & $\mathbf{8 5 . 2 1}$ & $\mathbf{1 7 9}$ & $\mathbf{1 4 1 . 4 3}$ & $\mathbf{2 4 1}$ & $\mathbf{1 1 7 . 4 7}$ & $\mathbf{4 2 0}$ \\
Upgrades & 90.39 & 35 & 133.34 & 74 & 119.55 & 109 \\
Reiterations & 83.61 & 122 & 146.48 & 148 & 118.07 & 270 \\
Downgrades & 85.83 & 22 & 133.54 & 19 & 107.94 & 41 \\
Hold & $\mathbf{8 9 . 0 0}$ & $\mathbf{1 4}$ & $\mathbf{1 4 1 . 7 6}$ & $\mathbf{5 3}$ & $\mathbf{1 3 0 . 7 4}$ & $\mathbf{6 7}$ \\
Upgrades & 66.51 & 1 & 176.95 & 1 & 121.73 & 2 \\
Reiterations & 92.75 & 7 & 128.37 & 19 & 118.78 & 26 \\
Downgrades & 88.34 & 6 & 148.41 & 33 & 139.17 & 39 \\
Sell & & & & & & \\
Reiterations & NA & NA & $\mathbf{1 3 1 . 6 3}$ & $\mathbf{1}$ & $\mathbf{1 3 1 . 6 3}$ & $\mathbf{1}$ \\
Strong Sell & NA & 131.63 & 1 & 131.63 & 1 \\
Downgrades & NA & NA & $\mathbf{1 0 5 . 6 4}$ & $\mathbf{2}$ & $\mathbf{1 0 5 . 6 4}$ & $\mathbf{2}$ \\
\hline
\end{tabular}

Notes to table 4: All results reported as percentages. 
TABLE 5

Percentage of Reports Achieving 12-Month Price Targets by Valuation Methodology

\begin{tabular}{|c|c|c|c|c|c|c|}
\hline & \multirow[b]{2}{*}{$\begin{array}{c}\text { Target } \\
\text { Achieved }\end{array}$} & \multicolumn{5}{|c|}{ Target Achieved In: } \\
\hline & & $\begin{array}{c}1 \text { to } 3 \\
\text { Months }\end{array}$ & $\begin{array}{c}4 \text { to } 6 \\
\text { Months }\end{array}$ & $\begin{array}{c}7 \text { to } 9 \\
\text { Months }\end{array}$ & $\begin{array}{l}10 \text { to } 12 \\
\text { Months }\end{array}$ & $\mathrm{N}$ \\
\hline \multicolumn{7}{|l|}{ All } \\
\hline Earnings Multiples & 54.24 & 30.87 & 13.16 & 6.64 & 3.57 & 813 \\
\hline DCF Variations & 51.37 & 23.85 & 16.51 & 6.42 & 4.59 & 109 \\
\hline Asset Multiples & 45.46 & 22.73 & 10.10 & 8.08 & 4.55 & 198 \\
\hline Other & 33.33 & 19.45 & 5.56 & 5.56 & 2.78 & 36 \\
\hline \multicolumn{7}{|l|}{ Upgrades } \\
\hline Earnings Multiples & 57.43 & 25.70 & 17.27 & 10.44 & 4.02 & 249 \\
\hline DCF Variations & 52.78 & 11.11 & 25.00 & 13.89 & 2.78 & 36 \\
\hline Asset Multiples & 59.32 & 22.03 & 22.03 & 8.47 & 6.78 & 59 \\
\hline Other & 42.86 & 14.29 & 0.00 & 28.57 & 0.00 & 7 \\
\hline \multicolumn{7}{|l|}{ Reiterations } \\
\hline Earnings Multiples & 50.62 & 30.91 & 11.41 & 5.19 & 3.11 & 482 \\
\hline DCF Variations & 45.61 & 21.05 & 14.03 & 3.51 & 7.02 & 57 \\
\hline Asset Multiples & 37.80 & 21.26 & 4.72 & 8.66 & 3.15 & 127 \\
\hline Other & 20.00 & 12.00 & 4.00 & 0.00 & 4.00 & 25 \\
\hline \multicolumn{7}{|l|}{ Downgrades } \\
\hline Earnings Multiples & 65.85 & 46.34 & 10.98 & 3.66 & 4.87 & 82 \\
\hline DCF Variations & 68.75 & 62.50 & 6.25 & 0.00 & 0.00 & 16 \\
\hline Asset Multiples & 58.33 & 41.67 & 8.33 & 0.00 & 8.33 & 12 \\
\hline Other & 100.00 & 75.00 & 25.00 & 0.00 & 0.00 & 4 \\
\hline
\end{tabular}

